\title{
Experimental Evaluation of Terminalia Arjuna (Aqueous Extract) On Cardiovascular System In Comparison To Digoxin
}

\author{
Dr. Prem Verma, Muneesh, Seema Rani, Garima Bhutani \\ Professor \& Head, Department of Pharmacology, BPS Government Medical College for Women \\ Khanpur Kalan (Sonepat), Haryana, India,
}

\begin{abstract}
Objective: To compare and evaluate the efficacy of Terminalia arjuna (aqueous extract) with digoxin on (i) Heart rate and amplitude of frog s heart in situ. (ii) Heart rate and amplitude of hypodynamic frog's heart in situ. (iii) Heart rate and amplitude of isolated perfused rabbit heart. (iv) Coronary flow of isolated perfused rabbit heart.

Methods: (i) The dried bark of Terminalia arjuna was Soxhlet extracted with distilled water. (ii) The Terminalia arjuna (aqueous extract) was evaluated for its effcacy on frog and rabbit heart. (iii) Efficacy of Terminalia (aqueous extract) was compared with digoxin in reference to above mentioned parameters.

Results: Terminalia arjuna (Aq.E) increased the force of contraction of cardiac muscle in frog's heart in situ, hypodynamic frog's heart in situ and isolated perfused rabbit heart. It also increased the coronary flow at a 400 $\mu g$ dose in isolated perfused rabbit heart along with dose dependent bradycardia. However the doses required were high as compared to digoxin so the agent proved to be less potent as compared to digoxin.

Conclusion: Terminalia arjuna (Aq.E) produced cardiotonic effects along with increase in the coronary flow in experimental animals where as its cholesterol lowering property has already been reported. So, it can be expected to be a good choice for CHF patients with hypercholesterolemia and requires further exploratory studies.
\end{abstract}

Key Words: Terminalia arjun (Aq.E), Soxhlet Extraction. CHF, Hypodynamic.

Running Title: Cardiovascular Evaluation of Terminalia Arjuna

\section{INTRODUCTION:}

Congestive heart failure (CHF) is a major public health problem in the United States. Nearly 5 million patients in this country suffer from CHF and nearly 500000 patients are diagnosed with CHF for the first time each year. Nearly 300000 patients die of CHF as a primary or contributory cause each year and the number of deaths has increased steadily despite advances in treatment. ${ }^{1}$ A number of medicinal plants have been described in ancient system of Indian Medicine which have been claimed to have beneficial cardiac effects. Terminalia arjuna is one of them. ${ }^{2}$ Terminalia arjuna belongs to the Combretaceae family and is a deciduous tree of 20-30 meters height found throughout India. ${ }^{3}$ Dwivedi and Agarwal have reported that administration of barkstem powder of Terminalia arjuna $500 \mathrm{mg} 8$ hrly to stable angina pectoris patients resulted in significant reduction in anginal episodes. ${ }^{4}$ Recently, Bharani et $\mathrm{al}^{5}$ have reported its beneficial effect on left ventricular ejection fraction (LVEF) in ischaemic cardiomyopathy. The utility of Terminalia arjuna in CHF has not been studied. The present study was undertaken to evaluate the effect of Terminalia arjuna on heart rate, amplitude and coronary flow of frog and rabbit heart and to compare it with digoxin, a known cardiac stimulant.

\section{Materials And Methods:}

EXTRACTION: The dried bark of Terminalia arjuna was Soxhlet extracted with distilled water. The aqueous extract was dried. The residue thus obtained was dissolved in distilled water for use in the present study.

Animals: The study was carried on frogs (125-150gms) and rabbits (1.5 to $2.5 \mathrm{~kg})$ of either sex. Eight animals were used for each set of experiments. Frogs were kept in clean tank of water provided with all the favourable environmental conditions. Preparations of physiological salt solutions used were frog ringer's solution and ringer solution. Rabbits were given uniform experimental conditions taking care of environment and diet.

The experiments were performed as per following methods:

1. Study on frog's heart in situ: An adult frog was mounted as per the method described by Burn. ${ }^{6}$ Sensitivity of the heart was tested by administering adrenaline hydrochloride solution $2 \mu \mathrm{g}$. Digoxin and Terminalia arjuna (Aq.E) were administered in graded doses. Their effects on perfused heart were observed regarding heart rate and amplitude. A total of sixteen such experiments were conducted and mean value calculated.

2. Study on hypodynamic frog's heart in situ: An adult frog was mounted as per the method described by Burn. ${ }^{6}$ Using three way cannula, one limb of cannula was connected to normal ringer solution and other was 
connected to frog ringer's solution containing $1 / 4 \mathrm{Cacl}_{2}$ as described by Kulkarni. ${ }^{7}$ Initially ringer containing $1 / 4 \mathrm{CaCl}_{2}$ was given and when the heart failed i.e. when the heart rate and force of contraction of heart decreased, the drug digoxin and Terminalia arjuna (Aq.E) were Cardiovascular Evaluation of Terminalia Arjuna 4given in graded doses. Effect of drugs on heart rate and amplitude was recorded. A total of sixteen such experiments were conducted and mean value canculated.

3. Study on isolated perfused rabbit heart: The rabbit heart was mounted as per the method described by Burn $^{6}$ and Perry. ${ }^{8}$ The heart was mounted in the Langendorff's assembly. The drugs digoxin and Terminalia arjuna (Aq.E) were given in graded doses. Heart rate was counted for 1 minute after the injection of each drug and effect observed. Amplitude of heart contractions was observed for 1 minute after injection of each drug. A total of sixteen such experiments were conducted and mean value calculated.

4. Study of coronary flow on isolated rabbit heart: The rabbit heart was mounted as described before in the Langendorff's assembly,as per methods described by Burn ${ }^{6}$ and Perry. ${ }^{8}$ The drugs digoxin and Terminalia arjuna (Aq.E) were given in graded doses and effect of drugs on coronary flow was observed. Coronary flow was estimated for 1 minute. A total of sixteen such experiments were conducted and mean value calculated.

Statistics: Mean value and standard error for all parameters were determined separately and put in tables as Mean \pm SE. Statistical significance between various groups, were analysed using student's ' $t$ ' test. ' $p$ ' value less than 1 in 20 ( $p<0.05)$ was considered significant and its value less than 1 in $100(p<0.01)$ was taken as highly significant. ' $p$ ' value calculated as less than 1 in $1000(p<0.001)$ was considered as very highly significant. If the value of ' $p$ ' was found to be more than 1 in 20 ( $p>0.05$ ), it was taken as insignificant.

\section{Results:}

In the present study, the test compound Terminalia arjuna (Aq.E) was pharmacologically investigated for its actions on cardiovascular system for cardiac stimulant effect. These effects were studied on frogs and rabbits. The cardiac stimulant effect of Terminalia arjuna was compared with that of digoxin. The preparations used were frog s heart in situ, hypodynamic frog's heart in situ and isolated perfused rabbit heart. Eight experiments of similar nature were carried out with graded doses of Terminalia arjuna (Aq.E) and digoxin for each experiment. In frogs heart in situ, digoxin caused no significant $(p>0.05)$ increase in heart rate and amplitude at all doses. Whereas Terminalia arjuna (Aq.E) produced statistically significant $(p<0.05)$ increase in HR $13.1 \%$ at $800 \mu \mathrm{g}$ dose only. Terminalia arjuna (Aq.E) produced significant $(\mathrm{p}<0.05)$ increase in amplitude $21.0 \%$ at $400 \mu \mathrm{g}$ and highly significant $(\mathrm{p}<0.01)$ increase in amplitude $21.4 \%$ and $21.3 \%$ at $200 \mu \mathrm{g}$ and $800 \mu \mathrm{g}$ doses respectively. In hypodynamic frog's heart in situ, Digoxin caused no significant $(\mathrm{p}>0.05)$ increase in HR at all doses. Digoxin caused significant $(p<0.05)$ increase in amplitude $13.7 \%$ and $14.3 \%$ at doses $10 \mu \mathrm{g}$ and $20 \mu \mathrm{g}$ respectively. Digoxin produced highly significant $(\mathrm{P}<0.01)$ increase in amplitude $17.5 \%$ and $13.9 \%$ at doses $5 \mu \mathrm{g}$ and $40 \mu \mathrm{g}$ respectively. Whereas Terminalia Cardiovascular Evaluation of Terminalia Arjuna 5

Arjuna (Aq.E) caused significant ( $<<0.05$ ) increase in HR $4.0 \%$ at $400 \mu \mathrm{g}$ dose only. Terminalia arjuna (Aq.E) produced significant $(\mathrm{p}<0.05)$ increase in amplitude $12.5 \%$ and $10.4 \%$ at doses $100 \mu \mathrm{g}$ and $400 \mu \mathrm{g}$ respectively, highly significant $(\mathrm{p}<0.01)$ increase in amplitude $14.9 \%$ at $800 \mu \mathrm{g}$ and very highly significant $(\mathrm{p}<0.001)$ increase in amplitude $12.5 \%$ at a dose of $200 \mu \mathrm{g}$. In isolated perfused rabbit heart, digoxin caused significant $(\mathrm{p}<0.05)$ increase in heart rate $3.7 \%$ at $5 \mu$ g dose only. Digoxin produced highly significant $(\mathrm{p}<0.01)$ increase in amplitude $43.1 \%, 32.3 \%$ and $52.8 \%$ at $5 \mu \mathrm{g}, 10 \mu \mathrm{g}$ and $40 \mu \mathrm{g}$ doses respectively. Digoxin produced very highly significant $(\mathrm{p}<0.001)$ increase in amplitude $28.6 \%$ at $20 \mu \mathrm{g}$ dose Digoxin produced significant $(\mathrm{p}<0.05)$ increase in coronary flow $9.3 \%$ at $10 \mu \mathrm{g}$, highly significant $(\mathrm{p}<0.01)$ increase in coronary flow $5.4 \%$ at $5 \mu \mathrm{g}$ and very highly significant $(\mathrm{p}<0.001)$ increase in coronary flow $11.5 \%$ at $20 \mu \mathrm{g}$ does .Terminalia arjuna (Aq.E) produced significant $(\mathrm{p}<0.05)$ increase in amplitude $26.7 \%$ at $100 \mu \mathrm{g}$, highly significant $(\mathrm{p}<0.01)$ increase in amplitude $25.3 \%$ at $200 \mu \mathrm{g}$ and very highly significant $(\mathrm{p}<0.001)$ increase in amplitude $36 \%$ and $33 \%$ at $400 \mu \mathrm{g}$ and $800 \mu \mathrm{g}$ doses respectively. Terminalia arjuna (Aq.E) caused significant $(\mathrm{p}<0.05)$ increase in corpnary flow $3.4 \%$ at $400 \mu \mathrm{g}$ only.

\section{Discussion:}

In the present study, Terminalia arjuna (Aq.E) increased the force of contraction of cardiac muscle in frog's heart in situ, hypodynamic frog's heart in situ and isolated perfused rabbit heart. Radhakrishnan et al ${ }^{9}$ had also reported that terminalia arjuna (Aq.E) produced a positive inotropic effect. Colabawalla ${ }^{10}$ and Antani et $\mathrm{al}^{11}$ reported improvement in patients of CHF. In a later study, Bharani et al ${ }^{5}$ also reported that Terminalia arjuna therapy in patients of refractory chronic congestive heart failure resulted in improvement of symptoms, signs and effort tolerance. This improvement in CHF reported in various clinical studies may be partly due to the 
positive inotropic effect of Terminalia arjuna. The mechanism underlying for increase in force of contraction is not very well known. This may be due to the various glycosides present in the bark of Terminalia arjuna as reported by Upadhyay et al. ${ }^{12}$ Terminalia arjuna (Aq.E) also caused dose- dependent bradycardia in isolated perfused rabbit heart. The maximum decrease in HR was observed in $800 \mu \mathrm{g}$. This is in accordance with the effect of Terminalia arjuna on isolated rat atria as reported by Srivastava et al. ${ }^{13}$ In addition to rise in force of contraction and bradycardia, a trend towards increase in the coronary flow of the isolated perfused rabbit heart was also observed. The coronary flow was enhanced at all the doses and it was maximum at a dose of $400 \mu \mathrm{g}$. This is also in agreement with the reports of increase in coronary flow of isolated perfused rabbit heart as reported by Bhatia. ${ }^{14}$ Dwivedi et al ${ }^{15}$ have reported that PGE- like activity is enhanced in ischaemic rabbit aorta. The enhancement of PGE- like activity by Terminalia arjuna may account to some extent for the observed rise in coronary flow. So, it is evident from the study that Terminalia arjuna (Aq.E) can be a useful tool in our hand for its use in congestive heart failure. However, Cardiovascular Evaluation of Terminalia Arjuna 6Terminalia arjuna is less potent as compared to digoxin because high doses were required in comparison to digoxin in different experiments. It also the decreased cholesterol levels, whereas no such effect is reported with digoxin. So, Terminalia arjuna can be useful in cases of CHF with hypercholesterolemia as reported by Ram et $\mathrm{al}^{16}$ without the disadvantage of narrow therapeutic range of digoxin along with bradycardia, vomiting, arrhythmias and other adverse effects. Further exploratory studies are required to establish its use in conditions like CHF and hypercholesterolemia.

\section{Acknowledgements:}

We are grateful to Dr. Subhash Modgill, Principal, Government Ayurvedic College, Patiala, for providing the barkstem powder of Terminalia arjuna and to Mr. D.K Sharma, Head, Department of Pharmacy, Government Medical, Patiala, for his expert guidance and help for preparing the aqueous extract of Terminalia arjuna.

\section{References:}

[1]. Haldman GA, Corft JB, Giles WH, Rashidec A. Hospitalization of patients with heart failure: National Discharge Survey,1985 to 1995. Am Heart J 1999; 137:352-60.

[2]. Sharma SB, Dwivedi S. Medicinial plants with hypolipidemic activities. Indian Drugs 1997; 34: 242-51.

[3]. Miller AL Botanical influences on cardiovascular disease. Alternative Medicine Review 1998; 3 (6): $422-31$.

[4]. Dwivedi S and Agarwal MP. Antianginal and cardioprotective effects of Terminalia arjuna, an indigenous drug in coronary artery disease. J. Assoc. Phys. India 1994;42:287-9.

[5]. Bharani A, Ganguly A, Bhargava KD. Salutary effect of Terminalia arjuna in patients with severe refractory heart failure. Int J Cardiol 1995; 49: 191-9.

[6]. Burn JH. Practical pharmacology, Blackwell Scientific publication, Oxford; 1952.p. 25, 30-31.

[7]. Kulkarni SK. Handbook of Experimental Pharmacology, Vallabh Prakashan, $3^{\text {rd }}$ Edition; 1999.p.158.

[8]. Perry WLM Pharamacological experiments on isolated preparations. E \& S. Livingstone, Edinburgh. $2^{\text {nd }}$ Edition; $1970 . p .116-7$.

[9]. Radhakrishnan R, Wadsworth RM, Gray Al. Terminalia arjuna an Ayurvedic cardiotonic, increases contractile force of rat isolated atria. Phytotherapy Res 1993; 7: 166-8.

[10]. Colabawalla HM. An evaluation of the cardiotonic and other properties of Terminalia arjuna. India Heart J 1951; $3: 205-30$.

[11]. Antani JA, Gandhi S, Antani NJ. Terminalia arjuna in congestive heart failure. J Assoc Phys India 1991; $39: 801$.

[12]. Upadhyay RK,Pandey MB, Jha RN, Singh VP, Panday VB, Triterpene glycoside from Terminalia arjuna. J Asian Nat Prod Res. 2001; 3 (3): 207-12.

[13]. Srivastava RD, Dwivedi S, Sreenivasan KK. Cardiovascular effects of Terminalia species of plants. Indian drugs 1992; 29:144-9.

[14]. Bhatia J. Study of the possible cardioprotective role of Terminalia arjuna in experimental animals and its clinical usefulness in coronary artery disease. MD Thesis. University of Delhi, 1998.

[15]. Dwivedi S, Chansouria JPN, Somani PN. Influence of certain indigenous drugs on the PGE-like activity in the ischemic rabbit aorta. India Drugs 1987; 24: 378-82.

[16]. Ram A, Lauria P, Gupta R, Kumar P, Sharma VN. Hypocholesterolemic effects of Terminalia arjuna tree bark. J Ethnopharmacol 1997; 55: 165-9.

Table 1

Cardiovascular Evaluation of Terminalia Arjuna 8

EFFECT OF TERMINALIA ARJUNA (Aq.E) ON HYPODYNAMIC

ERIG'S HEART IN SITU

Mean percentage change in Amplitude $(m m)(p$ value) $(n=8)$

\begin{tabular}{|c|c|c|c|c|}
\hline $\begin{array}{c}\text { Dose } \\
(\mu \mathrm{g})\end{array}$ & $\begin{array}{c}\text { Change in } \\
\text { Amplitude } \\
\text { Mean } \pm \text { SE } \\
\text { (before) }\end{array}$ & $\begin{array}{c}\text { Change in } \\
\text { Amplitude } \\
\text { Mean } \pm \text { SE } \\
(\text { After })\end{array}$ & $\begin{array}{l}\text { Mean } \\
\text { \%age } \\
\text { change }\end{array}$ & $\begin{array}{c}\mathrm{p} \\
\text { value }\end{array}$ \\
\hline 100 & $50.13 \pm 3.39$ & $56.38 \pm 3.94$ & $12.5 \uparrow$ & $<0.05$ \\
\hline 200 & $52.13 \pm 3.59$ & $58.63 \pm 3.78$ & $12.5 \uparrow$ & $<0.001$ \\
\hline 400 & $49.25 \pm 3.18$ & $54.38 \pm 4.48$ & $10.4 \uparrow$ & $<0.05$ \\
\hline 800 & $53.0 \pm 3.19$ & $60.88 \pm 4.41$ & $14.9 \uparrow$ & $<0.01$ \\
\hline
\end{tabular}


Table 2

EFFECT OF TERMINALIA ARJUNA (Aq.E) ON

ISOLATED PERFUSED RABBIT HEART

Mean percentage change in Amplitude ( $\mathrm{mm}$ ) ( $p$ value) $(n=8)$

\begin{tabular}{|c|c|c|c|c|}
\hline $\begin{array}{c}\text { Dose } \\
(\mu \mathrm{g})\end{array}$ & $\begin{array}{c}\text { Change in } \\
\text { Amplitude } \\
\text { Mean } \pm \text { SE } \\
\text { (before) }\end{array}$ & $\begin{array}{c}\text { Change in } \\
\text { Amplitude } \\
\text { Mean } \pm \text { SE } \\
(\text { After })\end{array}$ & $\begin{array}{c}\text { Mean } \\
\text { \%age } \\
\text { change }\end{array}$ & $\begin{array}{c}\mathrm{p} \\
\text { value }\end{array}$ \\
\hline 100 & $16.5 \pm 4.48$ & $20.88 \pm 5.58$ & $26.7 \uparrow$ & $<0.05$ \\
\hline 200 & $15.38 \pm 3.97$ & $19.25 \pm 4.69$ & $25.3 \uparrow$ & $<0.01$ \\
\hline 400 & $10.25 \pm 2.74$ & $14.0 \pm 3.03$ & $36.0 \uparrow$ & $<0.001$ \\
\hline 800 & $9.38 \pm 2.99$ & $12.5 \pm 3.07$ & $33.0 \uparrow$ & $<0.001$ \\
\hline
\end{tabular}

Cardiovascular Evaluation of Terminalia Arjuna 9 Mean Percentage Change in Amplitude of Hypodnamic Frog' Heart in situ with Terminalia Arjuna (Aq.E)

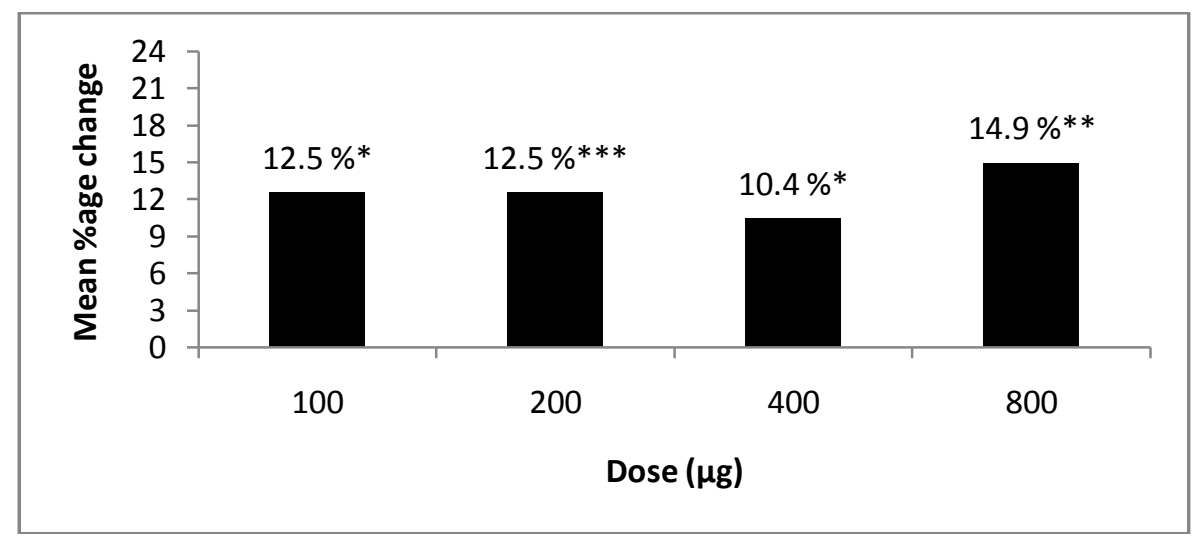

*Significant $\quad * *$ Highly Significant $\quad * * *$ Very Highly Significant

Mean Percentage Change in Amplitude of Isolated Perfused Rabbit Heart with Terminalia Arjuna (Aq.E)

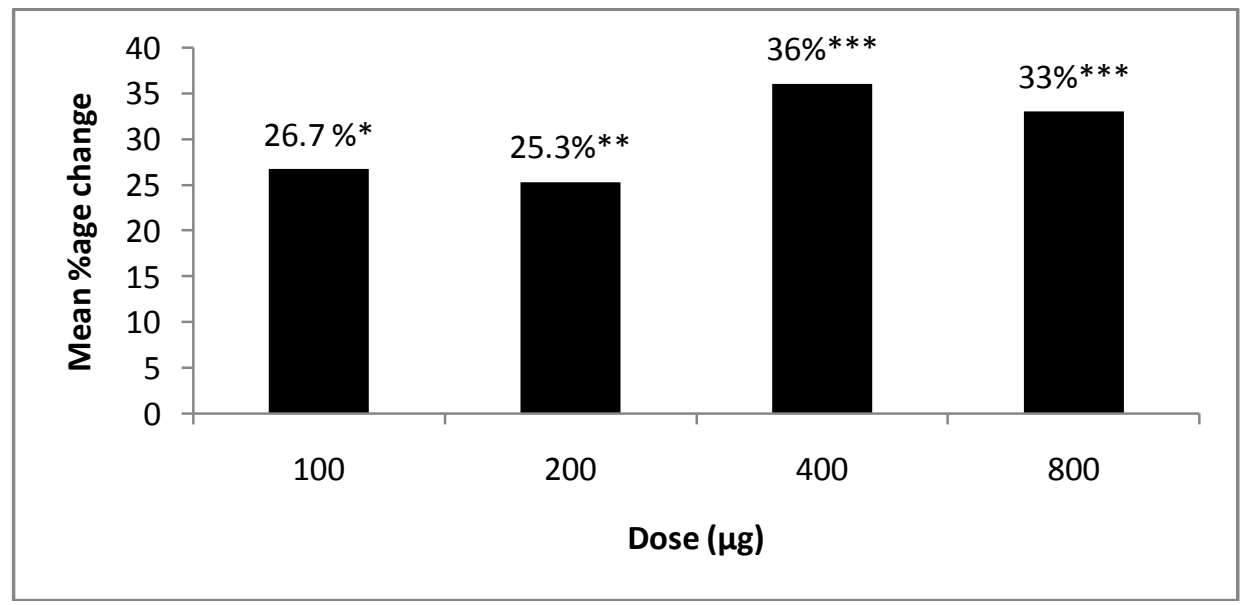

*Significant $\quad * *$ Highly Significant $\quad * * *$ Very Highly Significant 